\title{
Catalytic Degradation of Fluorouracil and Its Derivatives by Copper-Based Nanoparticles
}

\author{
Leah Javitt, Ishai Dror, ${ }^{*}$ and Brian Berkowitz \\ Department of Earth and Planetary Sciences, Weizmann Institute of Science, Rehovot, Israel.
}

Received: May 15, 2019 Accepted in revised form: August 14, 2019

\begin{abstract}
Fluorinated organic compounds (FOCs) are considered contaminants of emerging concern, and novel methods are required to achieve their degradation. 5-FU is a commonly used anticancer drug that is a representative example of a FOC. Use of copper-polyethylenimine nanoparticles (nCu-PEI) as a catalyst, with $\mathrm{H}_{2} \mathrm{O}_{2}$ as a radical source, is demonstrated for the degradation of 5-fluorouracil (5-FU). Optimal reaction conditions were found, and 5-FU was degraded completely within $24 \mathrm{~h}$, following first-order kinetics with a reaction rate of $0.003 \mathrm{~min}^{-1}$. Stoichiometric formation of $\mathrm{F}^{-}$was shown with the degradation of 5-FU. Substitution of uracil with other halogen groups led to a decrease in the reaction rate. By comparison, the rate of 5-Chlorouracil degradation was $0.002 \mathrm{~min}^{-1}$ and that of 5-Bromouracil degradation was $0.001 \mathrm{~min}^{-1}$. Stoichiometric formation of halogens was observed. A similar trend of decreasing reaction rate was found for the degradation of uracil in the presence of halogen salts. Results presented here suggest that this catalytic method can be an effective way to degrade FOCs.
\end{abstract}

Keywords: advanced oxidation process; Cu-PEI nanoparticles; emerging contaminants; fluorinated organic compounds

\section{Introduction}

I N RECENT YEARS, fluorinated organic compounds (FOCs) have been recognized as contaminants of emerging concern (Lai et al., 2016). The C-F bond of the FOCs is considered strong and very difficult to activate, thus leading to persistence of these compounds in the natural environment. As FOCs are becoming very common in new and nextgeneration pharmaceuticals, agrochemicals, and polymers, their environmental footprint is also growing (Campagnolo et al., 2002; Robinson et al., 2005). These emerging contaminants have been found in the wastewater, and even the groundwaters, in China, Japan, Thailand, Spain, and Germany (Lin et al., 2010; Shivakoti et al., 2010; Yang et al., 2011; Gómez-Canela et al., 2012).

One example of a FOC that is often detected in water resources is 5-Fluorouracil (5-FU), which is among the most prescribed anticancer cytostatic drugs. In particular, 5-FU and capecitabine, a 5-FU prodrug, are used to treat breast and colorectal cancer. While cytostatic drugs are taken up by the body, they are not fully metabolized and can be excreted in their original form, resulting in their introduction to the sewage system. These drugs reach waterways from hospitals,

*Corresponding author: Department of Earth and Planetary Sciences, Weizmann Institute of Science, Rehovot 7610001, Israel Phone: 972-8-9344230; Fax: 972-8-9344124; E-mail: ishai.dror@ weizmann.ac.il out-patient treatment centers, research centers, and even homes of patients (Zhang et al., 2013). Because these drugs, and others like them, do not biodegrade readily, it is imperative to develop effective and affordable wastewater treatment options. In addition, partially decomposing the drug is insufficient as there are not enough data to indicate that the degradation products are not harmful. In terms of presence in water resources, several reports confirm notable concentrations of 5-FU. In Slovenia, for example, 5-FU concentrations ranging from 35 to $92 \mathrm{ng} / \mathrm{L}$ have been measured in hospital wastewater, while concentrations of 4.7-14 ng/L were found in municipal wastewater treatment plants (Kosjek et al., 2013). Wastewater concentration of 5-FU in the Medical University of Vienna was estimated to range between 5 and $500 \mu \mathrm{g} / \mathrm{L}$ based on actual consumption and excretion, as well as wastewater volumes (Mahnik et al., 2004). Other estimates and measurements have yielded different values for the concentration of 5-FU in wastewater. The variation in the values can be attributed to the variation in 5-FU prescriptions in different countries, as well as differences in the factors used for the approximation, such as excretion rates and metabolism (Straub, 2007).

A study of the toxicity and mutagenicity of 5-FU on zebrafish found that at concentrations as low as $10 \mathrm{ng} / \mathrm{L}$, there were changes to the hematopoietic kidney tissue (Kovács et al., 2015). Other changes that were reported in the same study include chromosomal differences and changes in gene expression such as the downregulation of the major tumor 
suppressor gene p53. Effects on zebrafish were shown at levels that are an order of magnitude lower than the measured levels seen in hospital effluents (Kovács et al., 2015). Other investigations of the toxicity of 5-FU show chronic toxicity in other animals such as crustaceans and rotifers (Parrella et al., 2014). Using bacterial and algal assays, the lowest observed concentration for $5-\mathrm{FU}$ was $10 \mu \mathrm{g} / \mathrm{L}$, which is nearly the same level that can be expected to be found in wastewater (Zounková et al., 2007). Although these values do not relate to toxicity in humans, there is sufficient evidence to suggest ecological impacts of 5-FU.

5-FU is stable under natural sunlight conditions, but can degrade under UV light (Kosjek et al., 2013; Lutterbeck et al., 2016). Other studies found that 5-FU does not degrade in the presence of UV light without the addition of a photocatalyst (Lin and Lin, 2014). An analysis of the treatment products resulting from photodegradation showed that the majority of the degradation products retained the $\mathrm{C}-\mathrm{F}$ bond (Gómez-Canela et al., 2017). Even when $\mathrm{H}_{2} \mathrm{O}_{2}$ was introduced to the system, to increase the efficiency of photodegradation, the $\mathrm{C}-\mathrm{F}$ bond was not broken (Zhang et al., 2017). Conflicting results have been reported with regard to 5-FU biodegradation; Lutterbeck et al. $(2015,2016)$ reported that it does not biodegrade readily, while Kiffmeyer et al. (1998) reported complete degradation in a few days.

Another degradation method sometimes used in wastewater treatment is ozonation (Rice, 1996). 5-FU degrades rapidly when exposed to ozone (Lin et al., 2015). However, Lin et al. (2015) showed that other commonly used pharmaceuticals exhibited increased toxicity when degraded using ozone, and, significantly, the efficacy of degradation is strongly dependent on $\mathrm{pH}$, with a high $\mathrm{pH}$ being preferable (Lin et al., 2015).

Advanced oxidation processes have been shown to effectively break down numerous pollutants, including 5-FU. Using $\mathrm{TiO}_{2}$ as a photocatalyst and $\mathrm{H}_{2} \mathrm{O}_{2}, 5-\mathrm{FU}$ was successfully degraded, breaking the $\mathrm{C}-\mathrm{F}$ bond (Lutterbeck et al., 2015; Koltsakidou et al., 2017). $\mathrm{TiO}_{2}$ and $\mathrm{ZnO}$ have been shown to be effective photocatalysts when used in conjunction with $254 \mathrm{~nm}$ light (Lin and Lin, 2014). The addition of $\mathrm{H}_{2} \mathrm{O}_{2}$ has been shown to improve the effectiveness of advanced oxidation methods (Lutterbeck et al., 2015). Another method involving the electro-Fenton degradation of 5-FU also showed the formation of $\mathrm{F}^{-}$when in an acidic environment (Ganzenko et al., 2018). Fenton reaction was reported to effectively degrade 5-FU. However, when there is no exposure to light, the degradation products are more toxic than 5-FU (Governo et al., 2017). UV light can be used to improve the efficacy of the Fenton reaction, allowing for lower concentrations of iron ions and oxidant to be used (Lutterbeck et al., 2015; Governo et al., 2017). Iron as a Fenton reagent has the distinct disadvantage of being usable only in acidic environments, while copper can be used in a broad range of pH. In addition, organic complexes with $\mathrm{Cu}^{2+}$ are readily degraded by $\mathrm{OH}$, while similar complexes with $\mathrm{Fe}^{3+}$ are not (Bokare and Choi, 2014).

The main objective of this work was to study the degradation of 5-FU as a model fluorinated pharmaceutical compound, because of its environmental relevance. In addition, the availability of a homologous series of 5-FU (5Chlorouracil [5-ClU], 5-Bromouracil [5-BrU], and Uracil) allows broader understanding of the described degradation reaction mechanism. Our goal was to study degradation of 5-FU and its analogous chlorinated and brominated complexes, breaking of the $\mathrm{C}-\mathrm{F}$ bond, by copper oxide nanoparticles as catalysts and without the need for UV light or ozone. We further aimed to account for the possible formation of by-products containing a fluorine (or another halogen atom) - carbon bond. Therefore, both the degradation of the initial complex and the formation of free halogen ions were monitored throughout the reaction.

The degradation reaction was accomplished using a combination of a nanosized copper-based catalyst and $\mathrm{H}_{2} \mathrm{O}_{2}$. The optimal form of the catalyst, as well as the preferred concentrations of the catalyst and $\mathrm{H}_{2} \mathrm{O}_{2}$, was selected by varying these parameters and measuring the degradation of the reaction after $24 \mathrm{~h}$.

\section{Experimental}

\section{Materials}

The following materials were used in the study: nanosized copper oxide ( $\mathrm{nCuO}, \leq 50 \mathrm{~nm}$; CAS \#1317-38-0; Aldrich), 5-FU (99\%; CAS \#51-21-8; Sigma), $\mathrm{H}_{2} \mathrm{O}_{2}$ (30\% v/v; CAS \#7722-84-1; Frutarom), polyethylenimine (PEI; branched; MW 25,000 Da; CAS \#9002-98-6; Sigma-Aldrich), $\mathrm{Cu}\left(\mathrm{NO}_{3}\right)_{2} \cdot 3 \mathrm{H}_{2} \mathrm{O}$ (98\%; CAS \#10031-43-3; Fluka), $\mathrm{NaBH}_{4}$ (96\%; CAS \#16940-66-2; Aldrich), 5-ClU (99\%; CAS \#1820-81-1; Sigma), 5-BrU (99\%; CAS \#51-20-7; Sigma), Uracil (CAS \#66-22-8; Sigma), methanol (HPLC Grade; CAS \#67-56-1; J.T. Baker), and formic acid (98\%; CAS \#6418-6; J.T. Baker).

\section{Synthesis of CU-PEI nanoparticles}

The synthesis and characterization of the $\mathrm{Cu}$-PEI nanoparticles (nCu-PEI) catalysts used here were reported by Kalidhasan et al. (2017). Briefly, PEI (0.555 g) was first dissolved in $14 \mathrm{~mL}$ double distilled water (DDW). Then, $1.355 \mathrm{~g} \mathrm{Cu}\left(\mathrm{NO}_{3}\right)_{2} \cdot 3 \mathrm{H}_{2} \mathrm{O}$ was dissolved in $20 \mathrm{~mL}$ DDW. The $\mathrm{Cu}$ solution was added slowly to the PEI solution during stirring; an additional $46 \mathrm{~mL}$ DDW was then added. $\mathrm{NaBH}_{4}$ $(0.378 \mathrm{~g})$ was dissolved in $20 \mathrm{~mL} \mathrm{DDW}$; this solution was then added to the $\mathrm{Cu}$-PEI solution, and the solution was subsequently mixed for $1 \mathrm{~h}$. The solution was then divided into four portions, and each fraction underwent dialysis for $24 \mathrm{~h}$ in $800 \mathrm{~mL}$ DDW. The resulting suspension contained a copper concentration of $\sim 50 \mathrm{mM}$. Full characterization of the $\mathrm{nCu}-\mathrm{PEI}$, including $\mathrm{X}$-ray diffraction, zeta-potential measurements, light absorption spectra of the suspension, and transmission electron microscopy imaging, appears in (Kalidhasan et al., 2017). A summary of the major observations is provided in $\mathrm{Cu}$-PEI Nanoparticle Properties section of the Supplementary Data.

\section{Pre-experiment preparations}

Stock solutions of 5-FU, 5-ClU, 5-BrU, Uracil, each in concentration of $1.9 \mathrm{mM}$, and $\mathrm{nCu}-\mathrm{PEI}$ were prepared at the outset of the experiment. The initial concentration was selected to allow in-depth study of the reaction in a way that would enable tracking of the degradation, even when most of the 5-FU was degraded. Concentrations of the halogenated uracils were determined using a calibration curve; calibration curve solutions were also prepared at the outset of the 
experiment. Stock concentrations were stored at $4{ }^{\circ} \mathrm{C}$ and checked periodically to ensure that the analyte remained stable in solution and did not degrade. Before the experiment, limit of detection and limit of quantification for each analyte were determined to be 0.02 and $0.05 \mathrm{ppm}$, respectively. The $\mathrm{nCu}$-PEI were analyzed using differential light scattering to ensure a roughly narrow size distribution, as well as particle dimensions on the nanoscale (see Supplementary Fig. S8 for a representative size distribution diagram).

\section{Reaction with $\mathrm{nCuO}$ and $\mathrm{nCu}-\mathrm{PEI}$ catalysts}

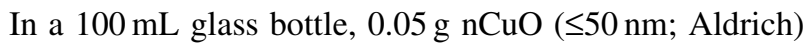
was combined with $95 \mathrm{~mL}$ of $1.88 \mathrm{mM} 5$-FU solution and sonicated for $0.5 \mathrm{~h} ; 5 \mathrm{~mL} \mathrm{H}_{2} \mathrm{O}_{2}$ solution was then added. In parallel, $1 \mathrm{~mL} \mathrm{nCu}$-PEI was combined with $46.5 \mathrm{~mL} 1.88 \mathrm{mM}$ 5-FU solution, and $2.5 \mathrm{~mL} \mathrm{H}_{2} \mathrm{O}_{2}(30 \%)$ solution was then added. This procedure led to an initial concentration of 5-FU of $1.88 \mathrm{mM}$, with $\mathrm{H}_{2} \mathrm{O}_{2}$ concentration of $5 \%$. The $\mathrm{nCuO}$ was added at a concentration of $0.4 \mathrm{~g} / \mathrm{L}$, which corresponds to a concentration of $5 \mathrm{mM} \mathrm{Cu}$. The nCu-PEI was added as $0-10 \%$ of the reaction solution, which corresponds to concentrations of $\mathrm{Cu}$ ranging from $\sim 0-5 \mathrm{mM}$. The lids were placed loosely on the reaction bottles to allow gases to escape; fluoride ion concentrations, which indicate breaking of the $\mathrm{C}-\mathrm{F}$ bond, and 5-FU concentrations were measured after 24 and $48 \mathrm{~h}$. The concentration was determined using calibration curves in the appropriate range. Samples were passed through $0.2 \mu \mathrm{m}$ syringe filters (Sartorius Stedim Biotech; Minisart). The same method was used with Uracil, 5-ClU, or 5 -BrU instead of 5-FU. It is further noted that all experiments were done at room temperature; in a previous analysis of similar catalytic systems (unpublished results), no substantial temperature effect was observed.

\section{HPLC conditions}

For 5-FU measurement: Waters 1525 binary HPLC pump was used with a Symmetry C18 $5 \mu \mathrm{m} 4.6 \times 250 \mathrm{~mm}$ column with dimethyloctadecylsilyl bonded amorphous silica and Waters 2487 dual $\lambda$ absorbance detector. The mobile phase was water:methanol $70: 30$ (v:v) with $0.1 \%$ formic acid of both phases; a flow rate of $0.4 \mathrm{~mL} / \mathrm{min}$ was used. The absorbance was measured at $266 \mathrm{~nm}$.

For $\mathrm{F}^{-}$measurement: Waters 1525 binary HPLC pump was used with a Hamilton PRP-X100 $10 \mu \mathrm{m} 2.1 \times 150 \mathrm{~mm}$ column and an Alltech conductivity detector Model 650. The mobile phase was $0.85 \mathrm{mM} \mathrm{NaHCO} 3$ in HPLC grade $\mathrm{H}_{2} \mathrm{O}$. The flow rate was $1.5 \mathrm{~mL} / \mathrm{min}$, although this was varied to maintain a pressure of 2000 psi.

For $\mathrm{Br}^{-}$and $\mathrm{Cl}^{-}$measurement: Waters 1525 binary HPLC pump was used with a Hamilton PRP-X100 $10 \mu \mathrm{m} 2.1 \times$ $150 \mathrm{~mm}$ column; an Alltech conductivity detector Model 650 was used. The mobile phase was $2.0 \mathrm{mM}$ sodium benzoate in HPLC grade $\mathrm{H}_{2} \mathrm{O}$. The flow rate was $1.5 \mathrm{~mL} / \mathrm{min}$, although this was varied to maintain a pressure of 2000 psi.

\section{Results and Discussion}

\section{Effect of catalyst type and concentration}

Figure 1 shows the effects of the type (nCuO vs. nCu-PEI) and concentration of copper-based nanosized catalysts, on the degradation of 5-FU and the breaking of the $\mathrm{C}-\mathrm{F}$ bond.

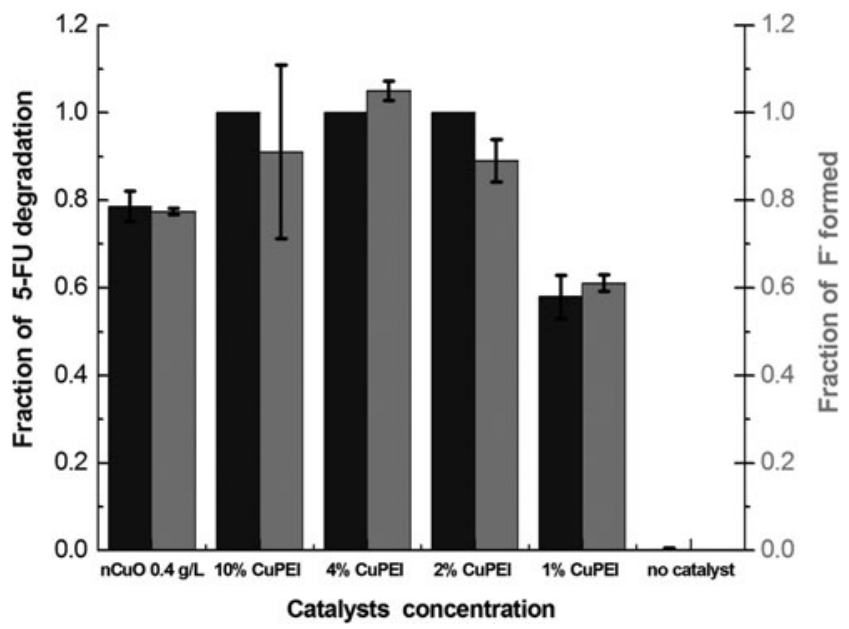

FIG. 1. Degradation of 5-FU and release of fluoride as reaction product comparing two copper-based nanocatalysts and varying concentrations of nCu-PEI. Reaction conditions: 5-FU concentration $1.88 \mathrm{mM}, 5 \% \mathrm{H}_{2} \mathrm{O}_{2}$, and reaction time $24 \mathrm{~h}$. Black columns: 5-FU degradation compared to initial concentration, related to the left axis; Gray columns: fluoride formation compared to available fluorine in the 5-FU initial concentration, related to the right axis. Note that error bars indicate one standard deviation. 5-FU, 5-fluorouracil; nCu-PEI, Cu-PEI nanoparticles.

The $y$-axis shows both the molar fraction of degraded 5-FU normalized by the initial 5-FU concentration and the molar fraction of $\mathrm{F}^{-}$ions formed normalized by the initial concentration of fluorine in solution. The effectiveness of nCuO, where copper is in the form of $\mathrm{Cu}(\mathrm{II})$, was compared to nCu-PEI synthesized with $\mathrm{Cu}(\mathrm{I})$ as reported in Kalidhasan et al. (2017). Both copper-based catalysts were selected because they have been shown to be effective for degradation of organic and halogenated organic compounds (Ben-Moshe et al., 2009; Fink et al., 2012; Yecheskel et al., 2013; Kalidhasan et al., 2017).

5-FU is stable and does not undergo any degradation without the addition of catalyst, as can be seen from Fig. 1. When $2-10 \%$ of nCu-PEI was used as catalyst, all 5-FU degraded and the formation of fluoride was almost stoichiometric, that is, in most cases, measurements lay within the small standard deviation range of the matching 5-FU and $\mathrm{F}^{-}$(Fig. 1). The ratio indicates that the $\mathrm{C}-\mathrm{F}$ bond was broken during the reaction and that this bond is the main (essentially sole) target of the reaction. When only $1 \% \mathrm{nCu}$-PEI was used, 5-FU was degraded but the reaction was not complete and $\sim 60 \%$ of the initial concentration was removed from the solution after $24 \mathrm{~h}$. For this case, too, the ratio of fluoride formation to 5-FU degradation was found to be stoichiometric, indicating that the degradation of 5-FU and formation of fluorides occur simultaneously. In comparison, the use of $\mathrm{nCuO}$ in molar concentration comparable to the highest nCu-PEI concentration yielded only $\sim 80 \%$ removal of 5-FU, but a stoichiometric formation of fluorides was found for this catalyst too.

Based on the results shown in Fig. 1, nCu-PEI was found to be a more efficient catalyst because lower concentrations could be used compared to nCuO. In addition, solutions of nCu-PEI are stable, making it easier to work with, and allowing for more control between experiments. The nCu-PEI 


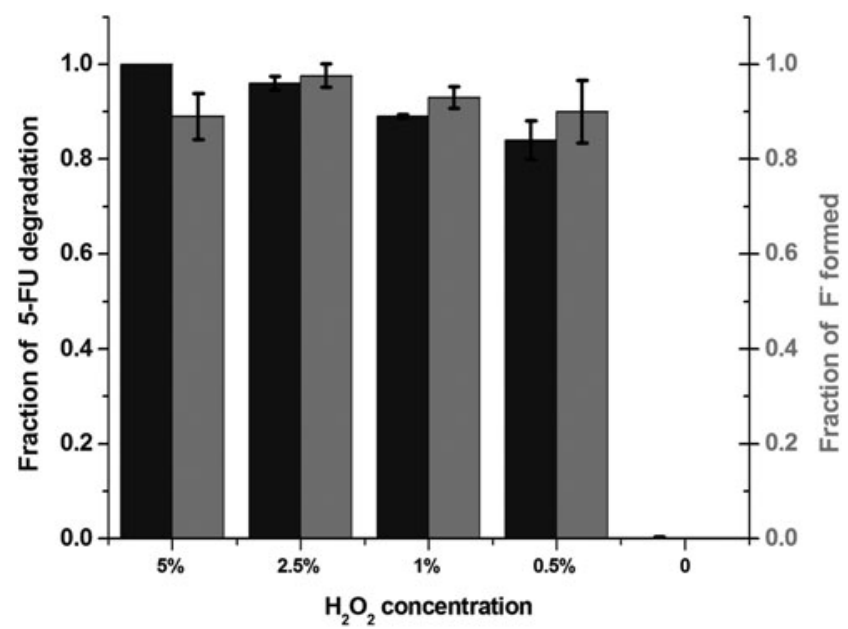

FIG. 2. Degradation of 5-FU and release of fluoride as reaction product as a function of varying concentrations of $\mathrm{H}_{2} \mathrm{O}_{2}$ reaction conditions: 5 -FU concentration $1.88 \mathrm{mM}, 5 \% \mathrm{H}_{2} \mathrm{O}_{2}$, and reaction time $24 \mathrm{~h}$. Black columns: 5-FU degradation compared to initial concentration, related to the left axis; Gray columns: fluoride formation compared to available fluorine in the 5-FU initial concentration, related to the right axis. Note that error bars indicate one standard deviation.

used in all replicates of the reactions was from a stock suspension synthesized at the outset of the study. Because the lowest concentration at which all the 5-FU was degraded was when a $2 \%$ solution of $\mathrm{nCu}-\mathrm{PEI}$ was used, this concentration was selected for the rest of the experiments.

\section{The effect of $\mathrm{H}_{2} \mathrm{O}_{2}$ concentration}

Once it was determined that the presence of the catalysts is critical to the degradation reaction, and the optimal concentration was determined for the experimental setup, the optimized $\mathrm{H}_{2} \mathrm{O}_{2}$ concentration was examined. Figure 2 shows the effect of varying the concentration of $\mathrm{H}_{2} \mathrm{O}_{2}$ between $0 \%$ and $5 \%$ on the degradation of 5-FU and formation of fluorides.
The only concentration that results in degradation of all 5-FU after $24 \mathrm{~h}$ is $5 \% \mathrm{H}_{2} \mathrm{O}_{2}$. In addition, the reaction with $0 \%$ $\mathrm{H}_{2} \mathrm{O}_{2}, 4 \%$ nCu-PEI, and $1.88 \mathrm{mM} 5-\mathrm{FU}$ showed no degradation. The addition of $0.5 \%, 1 \%, 2.5 \%$, and $5 \%$ resulted in degradation of $\sim 84 \%, 89 \%, 96 \%$, and $100 \%$ of $5-\mathrm{FU}$, respectively. The effect of $\mathrm{H}_{2} \mathrm{O}_{2}$ concentration is observed although $\mathrm{H}_{2} \mathrm{O}_{2}$ is in excess amount even at the lowest concentration. The higher concentration might have a small effect on the kinetics, and therefore, higher concentrations might be expected to result in faster degradation. In all cases, the degradation of 5-FU resulted in breaking the $\mathrm{C}-\mathrm{F}$ bond and stoichiometric formation of fluorides.

Figures 1 and 2 show no reaction for the controls of (1) no $\mathrm{nCu}-\mathrm{PEI}$ and (2) no $\mathrm{H}_{2} \mathrm{O}_{2}$. Because there is no change in the concentration of 5-FU with the addition of $\mathrm{nCu}-\mathrm{PEI}$ alone, it can be concluded that 5-FU does not adsorb onto the surface of the nanoparticles. It is worth noting that if reaction time is not a critical factor, lower concentrations of both reagents can be used, or if even shorter degradation times are required, higher concentrations can be used.

It is known that copper can react with $\mathrm{H}_{2} \mathrm{O}_{2}$ in a Fentonlike reaction (Pham et al., 2013). $\mathrm{Cu}(\mathrm{I})$ is oxidized by $\mathrm{H}_{2} \mathrm{O}_{2}$ resulting in the formation of the hydroxyl radical, while $\mathrm{Cu}$ (II) oxidizes $\mathrm{H}_{2} \mathrm{O}_{2}$ to form the superoxide; the reaction of $\mathrm{Cu}(\mathrm{I})$ with $\mathrm{H}_{2} \mathrm{O}_{2}$ can also result in the formation of $\mathrm{Cu}(\mathrm{III})$, another powerful oxidant (Nguyen et al., 2013; Pham et al., 2013). The generated radicals are then expected to be the oxidative reagents involved in the degradation of 5-FU.

\section{Degradation kinetics and reaction comparison to other uracil derivatives}

To better understand the reaction kinetics, the degradation of 5-FU and the formation of $\mathrm{F}^{-}$were measured in $30 \mathrm{~min}$ increments over the course of $8 \mathrm{~h}$, with a final measurement after being left overnight. Figure 3 shows a comparison of 5 FU degradation and $\mathrm{F}^{-}$formation as a function of time. Triplicate samples of $1.88 \mathrm{mM} 5$-FU solution containing $2 \%$ $\mathrm{nCu}$-PEI solution and $5 \% \mathrm{H}_{2} \mathrm{O}_{2}$ were used. It is seen that the points representing 5 -FU degradation (black squares) are

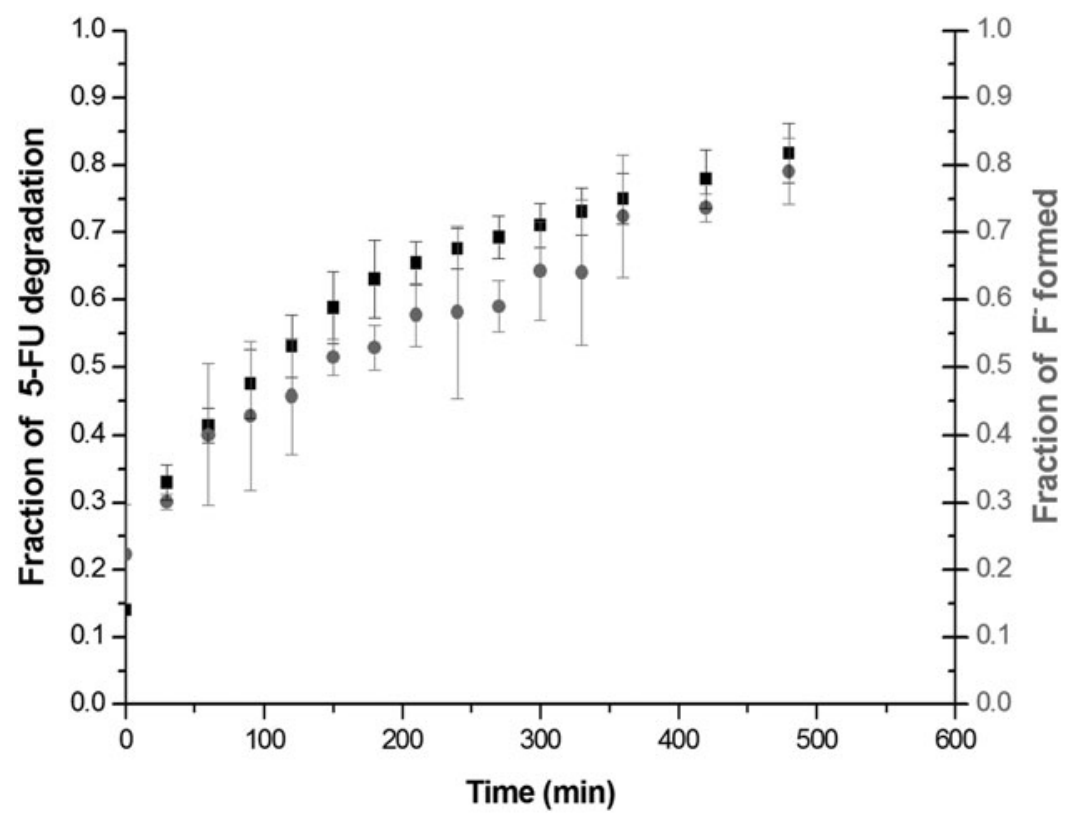

FIG. 3. 5-FU degradation (black squares) and $\mathrm{F}^{-}$formation (gray circles) versus time. Reaction conditions 5-FU concentration $1.88 \mathrm{mM}, 2 \% \mathrm{nCu}-\mathrm{PEI}$ solution, and $5 \%$ $\mathrm{H}_{2} \mathrm{O}_{2}$. Concentration of 5-FU is presented in molar \% relative to initial concentration (left axis), and $\mathrm{F}^{-}$concentrations are given in molar \% relative to initial fluorine concentration in the dissolved 5-FU (right axis). Note that error bars indicate one standard deviation. 
matched closely with the points representing $\mathrm{F}^{-}$formation (gray circles). This indicates that 5-FU was degraded and that defluorination occurred. Moreover, this result indicates that defluorination occurred as part of the degradation reaction, because there is no lag between the onset of 5-FU degradation and the formation of $\mathrm{F}^{-}$. After $8 \mathrm{~h}, \sim 80 \%$ of the 5 -FU was degraded; after $24 \mathrm{~h}$ the amount of 5-FU remaining was below the detection limit.

Analogous reactions were performed using 5-ClU and $5-\mathrm{BrU}$. The goal of performing this reaction with different halogenated organics was twofold: first, to show the versatility of this degradation process and, second, to help elucidate the mechanism of the reaction. As shown in Fig. $4 \mathrm{a}, \sim 70 \%$ of the 5-ClU degraded after $8 \mathrm{~h}$, and $\sim 95 \%$ of the 5 -ClU degraded after $24 \mathrm{~h}$. Similar to the degradation of 5-FU, the formation of $\mathrm{Cl}^{-}$closely matches the degradation of 5-CIU. The degradation reaction was also performed with $5-\mathrm{BrU}$, shown in Fig. 4b. After $8 \mathrm{~h}$, a little over $60 \%$ of the 5 -BrU degraded, and after $24 \mathrm{~h}, \sim 80 \%$ of the $5-\mathrm{BrU}$ had degraded. In this study, too, the formation of $\mathrm{Br}^{-}$is seen to closely match the degradation of 5-BrU.

The reaction conditions were identical for the 5-FU, 5-ClU, and 5-BrU degradation experiments. There was no formation of the uracil peak on the chromatogram, indicating that the $\mathrm{C}-\mathrm{X}$ bond is not the only one that is broken; rather, as expected, the entire molecule degrades. This is further evidenced by the degradation of uracil under the same reaction conditions. Representative chromatograms for all four derivatives, at the beginning, middle, and end of the reaction, which demonstrate the disappearance of the main peak and no formation of a new or any other peak, are provided in the Supplementary Data (Supplementary Figs. S4-S7).

The degradation reaction was also performed on unsubstituted uracil. This was done to determine if the halogens
FIG. 4. (a) 5-ClU degradation (black squares related to the left axis) and $\mathrm{Cl}^{-}$ formation (gray circles related to the right axis) versus time. (b) 5-BrU degradation (black squares) and $\mathrm{Br}^{-}$formation (gray circles) versus time. Reaction conditions $5-\mathrm{Br} / \mathrm{ClU}$ concentration $1.88 \mathrm{mM}, 2 \% \mathrm{nCu}-\mathrm{PEI}$ solution, and $5 \% \mathrm{H}_{2} \mathrm{O}_{2}$. The concentration of $5-\mathrm{Br} / \mathrm{ClU}$ is presented in molar fraction relative to initial concentration, and $\mathrm{Br}^{-} / \mathrm{Cl}^{-}$ concentration is given in molar fraction relative to initial bromine/chlorine concentration in the dissolved 5-FU. Note that error bars indicate one standard deviation. 5-BrU, 5-Bromouracil; 5-ClU, 5-Chlorouracil.
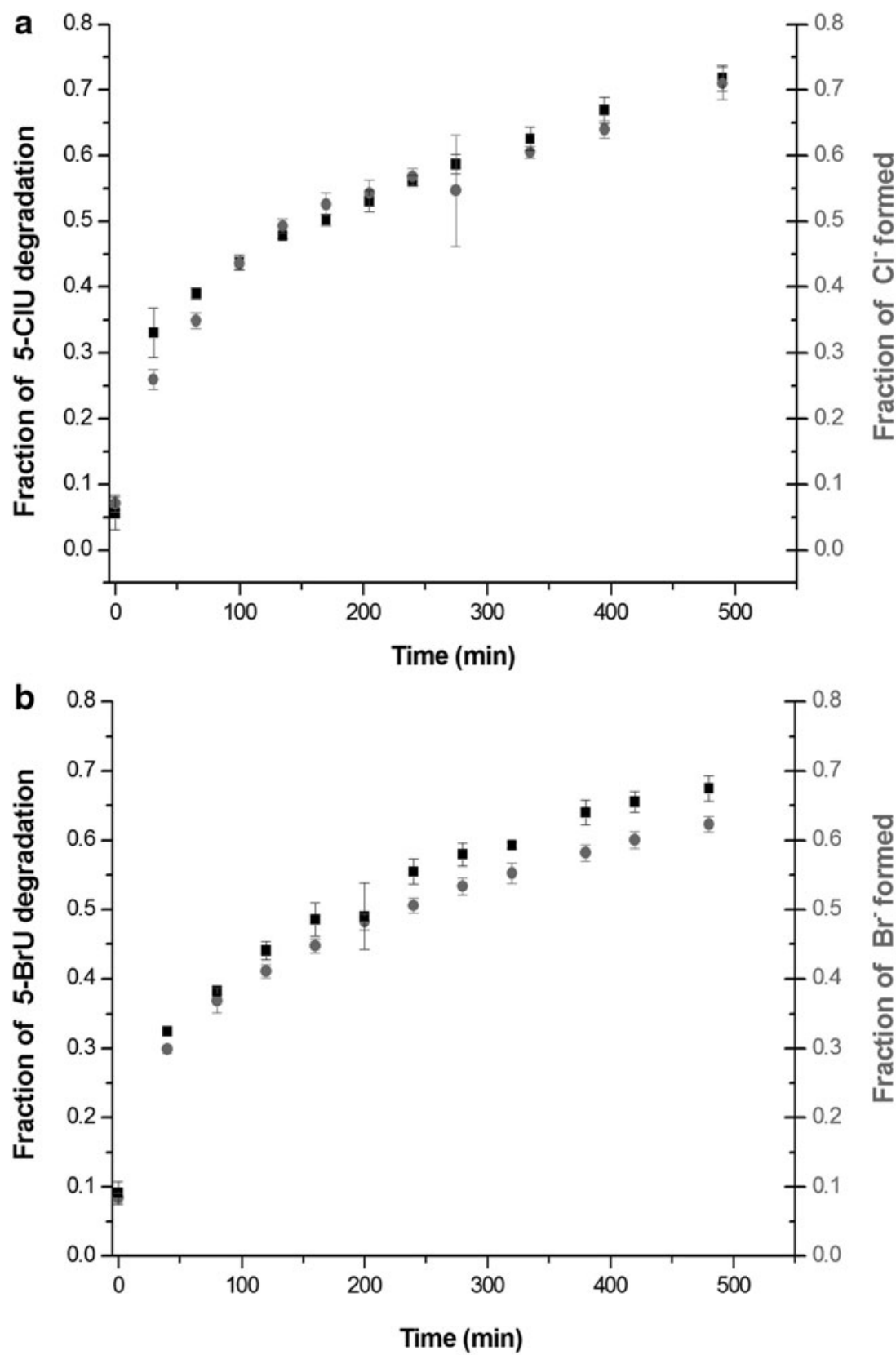


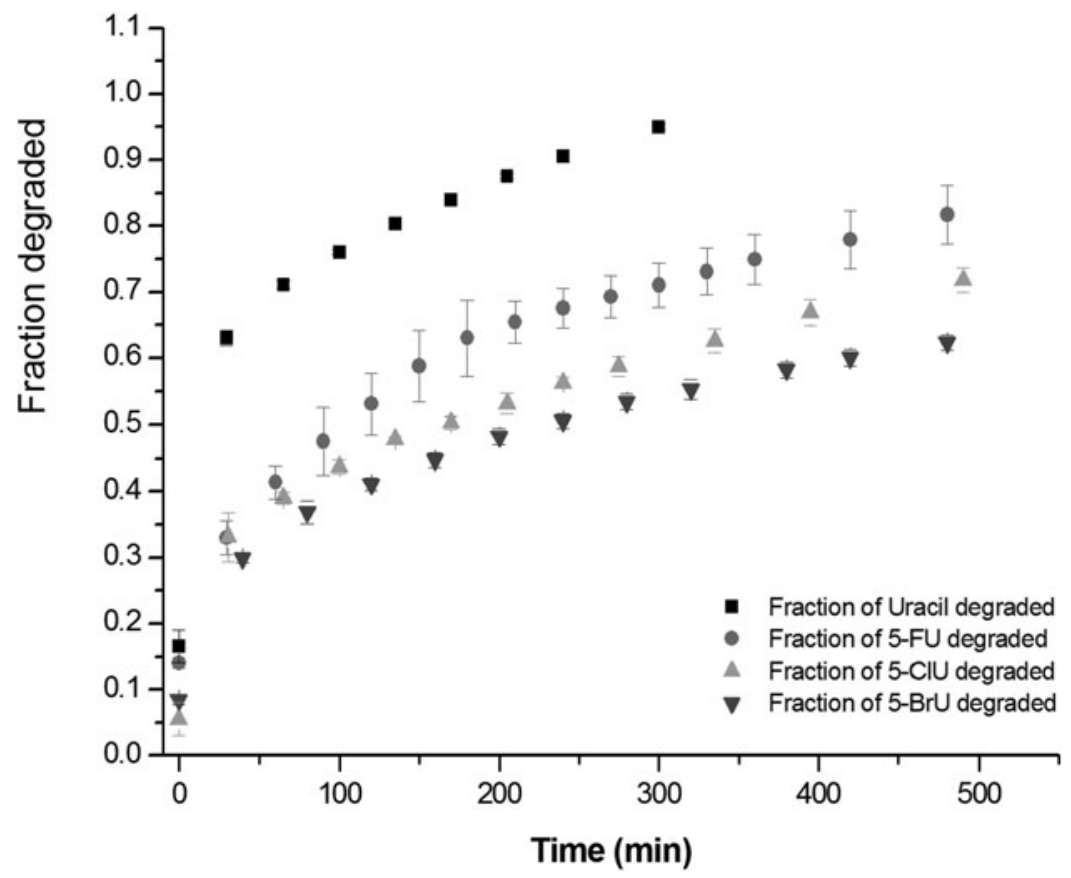

FIG. 5. Degradation of Uracil, 5-FU, 5-ClU, and 5-BrU versus time. Note that error bars indicate one standard deviation. were necessary for the degradation to occur, as well as to act as a control against which to compare the degradation reactions of the halogenated uracils. Figure 5 shows a comparison in reaction kinetics of uracil substituted with different halides. Interestingly, the reaction is the fastest for unsubstituted uracil, which was almost totally removed from solution after $5 \mathrm{~h}$. The degradation rate of uracil is followed by $5-\mathrm{FU}$, followed by 5-ClU and then 5-BrU. After 1 week, all three of the initial compounds were fully degraded and showed a stoichiometric halide formation. The reaction follows first-order kinetics for most of the reaction. Based on analysis of the curves in Fig. 5, the reaction rate for uracil was found to be $0.006 \mathrm{~min}^{-1}$, followed by 5 -FU with a reaction rate of $0.003 \mathrm{~min}^{-1}, 5-\mathrm{ClU}$ with a reaction rate of $0.002 \mathrm{~min}^{-1}$, and $5-\mathrm{BrU}$ with a reaction rate of $0.001 \mathrm{~min}^{-1}$. The reaction rate of the substituted uracil was found to decrease linearly with the decreasing electrophilicity index, $\omega$.

One possible explanation for the order of the degradation rates is that the halide forms a stable complex with $\mathrm{Cu}(\mathrm{I})$, preventing it from continuing its catalytic cycle by oxidizing to $\mathrm{Cu}$ (II). This is supported by the stability of the $\mathrm{Cu}$ (I)-halide complexes. The effect of halide presence on the oxidation rate of $\mathrm{Cu}(\mathrm{I})$ has been documented by Sharma and Millero (1988), showing a decrease in oxidation rate, and with the effect being more significant with $\mathrm{I}^{-}$than $\mathrm{Br}^{-}$, followed by $\mathrm{Cl}^{-}$(Sharma and Millero, 1988; Millero et al., 1992). This behavior is amplified by the scavenging effect of the halide on the hydroxyl radical. The larger the halide the less reactive is the formed reactive halogen species (Vleeschouwer et al., 2008). Removing hydroxyl radicals by forming reactive halogen species, which react much more selectively than hydroxyl radicals, would significantly slow the reaction rate. The importance of hydroxyl radical formation for the reaction rate is also seen in the preliminary experiments, where decreasing the concentration of $\mathrm{H}_{2} \mathrm{O}_{2}$ led to a decrease in degradation after $24 \mathrm{~h}$ (Fig. 2). The linkage of hydroxyl radical formation [as reported in Kalidhasan et al. (2017) and further discussed in the Supplementary Data] and the reaction rates is further supported by the much quicker reaction rate for the unsubstituted uracil. This suggested reaction mechanism implies that the critical step for the degradation of haloorganic molecules (specifically, the $\mathrm{C}-\mathrm{F}$ bond) progresses through the formation of hydroxyl radicals and not through the formation of other copper-peroxide reactive intermediaries for the reported catalytic setup. The relatively similar reaction patterns of the substituted halogens at the onset of the degradation reaction (first $60 \mathrm{~min}$ ), which diverge as the reaction progresses, in parallel to the increased release of halides to the solution, also fit the suggested explanation.

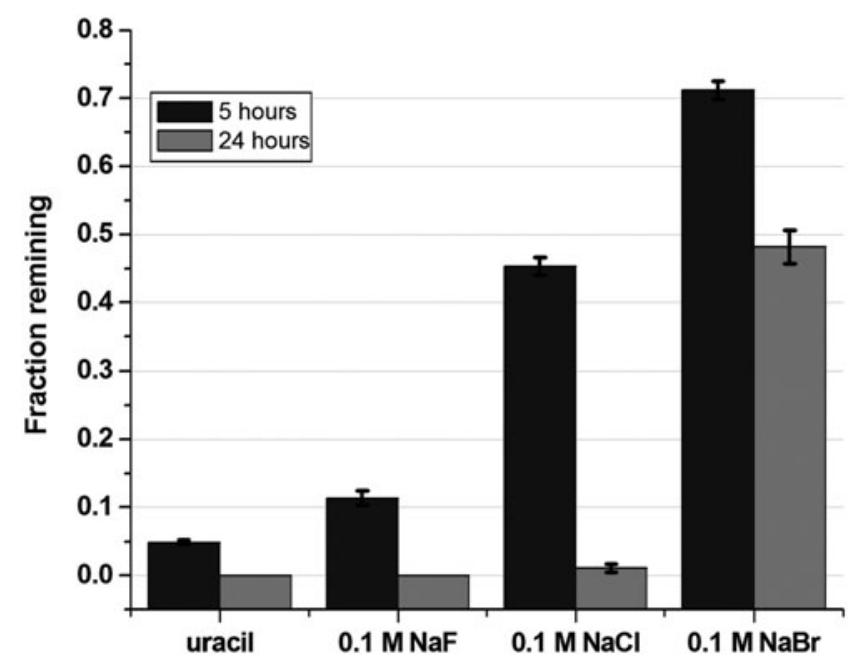

FIG. 6. Effect of different salts $(0.1 \mathrm{M}$ of $\mathrm{NaF}, \mathrm{NaCl}$, and $\mathrm{NaBr}$ ) on uracil degradation after $5 \mathrm{~h}$ (black columns) and $24 \mathrm{~h}$ (gray columns) reaction. At $24 \mathrm{~h}$, uracil concentrations were below detection limits for the no salt and $0.1 \mathrm{M} \mathrm{NaF}$ conditions. Note that error bars indicate one standard deviation. 


\section{Effect of ions in reaction solution}

To measure the effects of additional halogen ions on the degradation reaction, $0.1 \mathrm{M} \mathrm{NaF}, \mathrm{NaCl}$, and $\mathrm{NaBr}$ were added to the degradation reaction of uracil with $\mathrm{H}_{2} \mathrm{O}_{2}$ and $\mathrm{nCu}$-PEI. The fraction of remaining uracil was measured after 5 and $24 \mathrm{~h}$. The results are shown in Fig. 6. The $\mathrm{NaBr}$ inhibited the degradation of uracil with $71 \%$ remaining after $5 \mathrm{~h}$ and $48 \%$ remaining after $24 \mathrm{~h}$. With the addition of $\mathrm{NaCl}$, $45 \%$ of the uracil remained after $5 \mathrm{~h}$, but only $1 \%$ remained after $24 \mathrm{~h}$. The addition of $\mathrm{NaF}$ inhibited the reaction the least, with only $11 \%$ remaining after $5 \mathrm{~h}$, and there was no measurable uracil after $24 \mathrm{~h}$. Without the addition of salts, $\sim 5 \%$ uracil remained after $5 \mathrm{~h}$, and no measurable uracil remained after $24 \mathrm{~h}$.

These findings can be viewed in conjunction with Fig. 5, which displays the kinetics of the degradation reactions of uracil, fluorouracil, chlorouracil, and bromouracil. The trends of uracil degradation dynamics in the presence of halide salts support the posited reasoning that the degradation rates for the halogenated uracils are slower due to effects of having free halogens in solution, and not only because of the nature of the organo-halide bond.

\section{Conclusions}

FOCs are considered persistent contaminants of emerging concern. Their applications are diverse, and large volumes are being produced and used in the agrochemical, polymer, and pharmaceutical industry. These substances possess many appealing properties, but once their beneficial use is finished, they often remain or are released to the environment. Therefore, the need for methods that can break down the FOCs, especially the $\mathrm{C}-\mathrm{F}$ bond, is crucial. In this study, we demonstrated the use of $\mathrm{nCu}-\mathrm{PEI}$ as a catalyst for 5-FU degradation. The reaction conditions were optimized by varying the catalyst and $\mathrm{H}_{2} \mathrm{O}_{2}$ concentration. A study of the kinetics of the reaction was performed and was found to follow first-order kinetics. The effects of substitution of uracil with different halogens were also investigated; halogens, that are lower down in column VII of the periodic table, were found to slow the degradation rate. The same effect on the degradation rate of uracil was observed with the addition of an ionic salt. Overall, $\mathrm{nCu}-\mathrm{PEI}$ was found to be an effective catalyst for the degradation of 5-FU.

The results indicate that the nCu-PEI catalyst is capable of degrading $\mathrm{C}-\mathrm{F}$ bonds. It was further shown that fluorinated compounds degrade preferably by this method, compared to other halogenated compounds. Finally, we note that the catalytic method presented here is effective at ambient temperature and pressure. The fact that 5-FU is fully removed and no substantial by-product was detected suggest that oxidation with $\mathrm{nCu}-\mathrm{PEI}$ catalysts could be an environmentally acceptable method to degrade FOCs.

\section{Author Disclosure Statement}

No competing financial interests exist.

\section{Funding Information}

The authors gratefully acknowledge support by a research grant from Stanley Magidson.

\section{Supplementary Material}

Supplementary Data

\section{References}

Ben-Moshe, T., Dror, I., and Berkowitz, B. (2009). Oxidation of organic pollutants in aqueous solutions by nanosized copper oxide catalysts. Appl. Catal. B 85, 207.

Bokare, A.D., and Choi, W. (2014). Review of iron-free Fentonlike systems for activating $\mathrm{H}_{2} \mathrm{O}_{2}$ in advanced oxidation processes. J. Haz. Mat. 275, 121.

Campagnolo, E.R., Johnson, K.R., Karpati, A., Rubin, C.S., Kolpin, D.W., Meyer, M.T., Esteban, J.E., Currier, R.W., Smith, K., Thu, K.M., and McGeehin, M. (2002). Antimicrobial residues in animal waste and water resources proximal to large-scale swine and poultry feeding operations. Sci. Tot. Environ. 299, 89.

Fink, L., Dror, I., and Berkowitz, B. (2012). Enrofloxacin oxidative degradation facilitated by metal oxide nanoparticles. Chemosphere 86, 144.

Ganzenko, O., Oturan, N., Sirés, I., Huguenot, D., van Hullebusch, E.D., Esposito, G., and Oturan, M.A. (2018). Fast and complete removal of the 5-fluorouracil drug from water by electro-Fenton oxidation. Environ. Chem. Lett. 16, 281.

Gómez-Canela, C., Barth, J.A.C., and Lacorte, S. (2012). Occurrence and fate of perfluorinated compounds in sewage sludge from Spain and Germany. Environ. Sci. Pollut. Res. $19,4109$.

Gómez-Canela, C., Bolivar-Subirats, G., Tauler, R., and Lacorte, S. (2017). Powerful combination of analytical and chemometric methods for the photodegradation of 5Fluorouracil. J. Pharm. Biomed. Anal. 137, 33.

Governo, M., Santos, M.S.F., Alves, A., and Madeira, L.M. (2017). Degradation of the cytostatic 5-Fluorouracil in water by Fenton and photo-assisted oxidation processes. Environ. Sci. Pollut. Res. Int. 24, 844.

Kalidhasan, S., Ben-Sasson, M., Dror, I., Carmieli, R., Schuster, E.M., and Berkowitz, B. (2017). Oxidation of aqueous organic pollutants using a stable copper nanoparticle suspension. Can. J. Chem. Eng. 95, 343.

Kiffmeyer, T., Götze, H.-J., Jursch, M., and Lüders, U. (1998). Trace enrichment, chromatographic separation and biodegradation of cytostatic compounds in surface water. Fresenius J. Anal. Chem. 361, 185.

Koltsakidou, A., Antonopoulou, M., Evgenidou, E., Konstantinou, I., Giannakas, A.E., Papadaki, M., Bikiaris, D., and Lambropoulou, D.A. (2017). Photocatalytical removal of fluorouracil using $\mathrm{TiO}_{2}-\mathrm{P}_{25}$ and $\mathrm{N} / \mathrm{S}$ doped $\mathrm{TiO}_{2}$ catalysts: A kinetic and mechanistic study. Sci. Total Environ. 578, 257.

Kosjek, T., Perko, S., Žigon, D., and Heath, E. (2013). Fluorouracil in the environment: Analysis, occurrence, degradation and transformation. J. Chromat. A 1290, 62.

Kovács, R., Csenki, Z., Bakos, K., Urbányi, B., Horváth, Á., Garaj-Vrhovac, V., Gajski, G., Gerić, M., Negreira, N., López de Alda, M., Barceló, D., Heath, E., Kosjek, T., Žegura, B., Novak, M., Zajc, I., Baebler, Š., Rotter, A., Ramšak, Ž., and Filipič, M. (2015). Assessment of toxicity and genotoxicity of low doses of 5-fluorouracil in zebrafish (Danio rerio) twogeneration study. Water Res. 77, 201.

Lai, W.W.P., Lin, Y.C., Tung, H.H., Lo, S.L., and Lin, A.Y.C. (2016). Occurrence of pharmaceuticals and perfluorinated compounds and evaluation of the availability of reclaimed water in Kinmen. Emerg. Contam. 2, 135. 
Lin, A.Y.C., Hsueh, J.H.F., and Hong, P.K.A. (2015). Removal of antineoplastic drugs cyclophosphamide, ifosfamide, and 5-fluorouracil and a vasodilator drug pentoxifylline from wastewaters by ozonation. Environ. Sci. Pollut. Res. Int. 22, 508.

Lin, A.Y.C., Panchangam, S.C., and Ciou, P.S. (2010). High levels of perfluorochemicals in Taiwan's wastewater treatment plants and downstream rivers pose great risk to local aquatic ecosystems. Chemosphere 80, 1167.

Lin, H.H.H., and Lin, A.Y.C. (2014). Photocatalytic oxidation of 5-fluorouracil and cyclophosphamide via $\mathrm{UV} / \mathrm{TiO}_{2}$ in an aqueous environment. Water Res. 48, 559.

Lutterbeck, C.A., Wilde, M.L., Baginska, E., Leder, C., Machado, E.L., and Kümmerer, K. (2016). Degradation of cyclophosphamide and 5-fluorouracil by UV and simulated sunlight treatments: Assessment of the enhancement of the biodegradability and toxicity. Environ. Pollut. 208, 467.

Lutterbeck, C.A., Wilde, M.L., Baginska, E., Leder, C., Machado, Ê.L., and Kümmerer, K. (2015). Degradation of 5-FU by means of advanced (photo)oxidation processes: $\mathrm{UV} / \mathrm{H}_{2} \mathrm{O}_{2}$, $\mathrm{UV} / \mathrm{Fe}^{2+} / \mathrm{H}_{2} \mathrm{O}_{2}$ and $\mathrm{UV} / \mathrm{TiO}_{2}-$ Comparison of transformation products, ready biodegradability and toxicity. Sci. Tot. Environ. 527, 232.

Mahnik, S., Rizovski, B., Fuerhacker, M., and Mader, R. (2004). Determination of 5-fluorouracil in hospital effluents. Anal. Bioanal. Chem. 380. DOI:10.1007/s00216-004-2727-6

Millero, F.J., Johnson, R.L., Vega, C.A., Sharma, V.K., and Sotolongo, S. (1992). Effect of ionic interactions on the rates of reduction of $\mathrm{Cu}$ (II) with $\mathrm{H}_{2} \mathrm{O}_{2}$ in aqueous solutions. $J$. Solut. Chem. 21, 1271.

Nguyen, T.T.M., Park, H.J., Kim, J.Y., Kim, H.E., Lee, H., Yoon, J., and Lee, C. (2013). Microbial inactivation by cupric ion in combination with $\mathrm{H}_{2} \mathrm{O}_{2}$ : Role of reactive oxidants. Environ. Sci. Technol. 47, 13661.

Parrella, A., Lavorgna, M., Criscuolo, E., Russo, C., Fiumano, V., and Isidori, M. (2014). Acute and chronic toxicity of six anticancer drugs on rotifers and crustaceans. Chemosphere 115, 59.

Pham, A.N., Xing, G., Miller, C.J., and Waite, T.D. (2013). Fenton-like copper redox chemistry revisited: Hydrogen peroxide and superoxide mediation of copper-catalyzed oxidant production. J. Catal. 301, 54.

Rice, R.G. (1996). Applications of ozone for industrial wastewater treatment-A review. Ozone: Sci. Eng. 18, 477.

Robinson, A.A., Belden, J.B., and Lydy, M.J. (2005). Toxicity of fluoroquinolone antibiotics to aquatic organisms. Environ. Toxicol. Chem. 24, 423.

Sharma, V.K., and Millero, F.J. (1988). Determining the stability constant of copper(I) halide complexes from kinetic measurements. Inorg. Chem. 27, 3256.

Shivakoti, B.R., Tanaka, S., Fujii, S., Kunacheva, C., Boontanon, S.K., Musirat, C., Seneviratne, S.T.M.L.D., and Tanaka, H. (2010). Occurrences and behavior of perfluorinated compounds (PFCs) in several wastewater treatment plants (WWTPs) in Japan and Thailand. J. Environ. Monitor. 12, 1255.

Straub, J.O. (2007). Combined environmental risk assessment for 5-fluorouracil and capecitabine in Europe. Integr. Environ. Assess. Manage, 1. DOI:10.1897/IEAM_2009-073.1

Vleeschouwer, F.D., Speybroeck, V.V., Waroquier, M., Geerlings, P., and Proft, F.D. (2008). An intrinsic radical stability scale from the perspective of bond dissociation enthalpies: A companion to radical electrophilicities. J. Org. Chem. 73, 9109.

Yang, L., Zhu, L., and Liu, Z. (2011). Occurrence and partition of perfluorinated compounds in water and sediment from Liao River and Taihu Lake, China. Chemosphere 83, 806.

Yecheskel, Y., Dror, I., and Berkowitz, B. (2013). Catalytic degradation of brominated flame retardants by copper oxide nanoparticles. Chemosphere 93, 172.

Zhang, J., Chang, V.W.C., Giannis, A., and Wang, J.Y. (2013). Removal of cytostatic drugs from aquatic environment: A review. Sci. Tot. Environ. 445, 281.

Zhang, Y., Xiao, Y., Zhang, J., Chang, V.W.C., and Lim, T.T. (2017). Degradation of cyclophosphamide and 5-fluorouracil in water using $\mathrm{UV}$ and $\mathrm{UV} / \mathrm{H}_{2} \mathrm{O}_{2}$ : Kinetics investigation, pathways and energetic analysis. J. Environ. Chem. Eng. 5, 1133. Zounková, R., Odráška, P., Dolealová, L., Hilscherová, K., Maršálek, B., and Bláha, L. (2007). Ecotoxicity and genotoxicity assessment of cytostatic pharmaceuticals. Environ. Toxicol. Chem. 26, 2208. 